\title{
KEANEKARAGAMAN SEMUT (HYMENOPTERA: FORMICIDAE) PADA BERBAGAI SUBZONA HUTAN PEGUNUNGAN DI SEPANJANG JALUR PENDAKIAN CIBODAS, TAMAN NASIONAL GUNUNG GEDE- PANGRANGO (TNGGP)
}

\author{
Irfanul Arifin \\ Program Studi Biologi FMIPA Universitas Negeri Jakarta, Indonesia \\ Email: -
}

\begin{abstract}
The existence of ants in the nature are influenced by biotic and abiotic components. Different of conditions in a habitat determine biodiversity inside, belonging to ants diversity. This research was aim to know diversity, richness, and distribution of ants in various Mountain Forest Subzone in along Cibodas Climbing Track, TNGGP, was first study about ants of TNGGP because no previous research was held so that can becomed reference for next research and conservation step. The using method was descriptive with survey technique use pit fall trap by alcohol was located in 3 mountain forest subzones for 6 position that is Telaga Biru, Cibeureum waterfall, Air Panas, Kandang Badak, Mount Gede Summit, and Alun-Alun Suryakencana. This research was identified 4 subfamilies and 12 species. Diversity index of submontane, montane, and subalpine forest severally about 1,568; 1,347; and 0,676.
\end{abstract}

Key words: ants diversity, Cibodas climbing track, montane, pit fall trap, subalpine, submontane

\section{PENDAHULUAN}

Indonesia memiliki 250.000 jenis serangga atau sekitar 15\% dari jumlah jenis biota utama yang diketahui di Indonesia (Bappenas, 1993, dalam Shabuddin, 2005). Semut adalah serangga eusosial yang berasal dari Famili Formicidae yang termasuk dalam Ordo Hymenoptera bersama dengan lebah dan tawon serta kosmopolit (Borror et al., 1996). Ada sekitar 3500 spesies yang hidup di daerah tropis dan beriklim sedang (Hoeve, 1996). Saat jumlah mereka bertambah, mereka dapat membentuk sekitar 15-20\% jumlah biomassa hewan-hewan besar (Schultz, 2000).

Semut memiliki peran sangat penting di ekosistem. Semut adalah pemangsa utama beberapa invertebrata kecil. Selain sebagai pemangsa, semut juga mangsa penting bagi hewan lainnya bahkan bagi tumbuhan sekali pun (Borror et al, 1996). Semut dapat menjaga aerasi dan pencampuran tanah sehingga meningkatkan infiltrasi air yang menyebabkan tanah tetap sehat. Semut membentuk simbiosis dengan serangga lainnya, tumbuhan, maupun fungi. Banyak spesies semut yang juga aktif menyebarkan bibit berbagai jenis tanaman (Hoeve, 1996). Peran ini sedemikian penting sehingga dapat dikatakan jika semut punah, ribuan spesies hewan dan tumbuhan akan ikut punah. Bahkan lebih dari itu, hampir semua ekosistem daratan akan melemah karena berkurangnya kompleksitas ekosistem (Hoeve, 1996). 
Keberadaan semut sangat dipengaruhi oleh komponen biotik dan abiotik yang ada di habitatnya. Perbedaan kondisi dari suatu habitat menentukan jenis makhluk hidup yang berada di dalamnya, termasuk semut. Di sepanjang Jalur Pendakian Cibodas, ditemukan berbagai subzona hutan pegunungan seperti submontana, montana, dan subalpin yang masing-masing memiliki kekhasan dan karakteristik tersendiri. Kondisi ini tentu akan mempengaruhi keaneragaman hayati di dalamnya. Oleh karena itu, perlu dilakukan suatu kajian untuk mencari tahu keanekaragaman semut pada masing-masing subzona hutan pegunungan tersebut dan melihat pembagian peranan di dalamnya.

\section{METODE PENELITIAN}

Pengambilan sampel dilakukan selama 3 minggu pada Bulan Juni 2012 di sepanjang jalur pendakian Cibodas menuju Alun-Alun Suryakencana, Taman Nasional Gunung Gede-Pangrango. Penelitian ini dilakukan dengan metode deskriptif menggunakan teknik survey.

Alat dan bahan yang digunakan di antaranya botol koleksi, pinset, cawan petri, sekop, kertas label, kotak koleksi, kaca pembesar, mistar, mikroskop stereo, kamera digital Fuji Film Finepix T200 14 mega pixels, kertas minyak, kertas label, kompas, altimeter Sunoh SAL7020, soil pH tester Takemura DM-13, weather meter Kestrel 3000, Global Positioning System (GPS) Garmin eTrex Legend Cx, aquades, alkohol 70\%, dan gliserin.

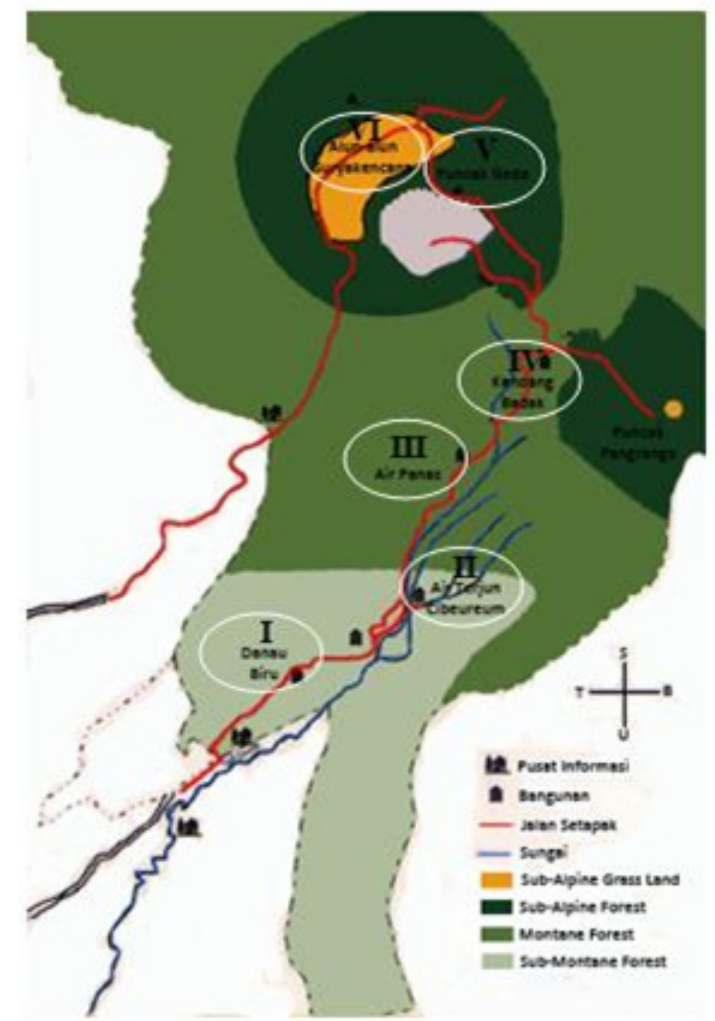

Gambar 1. Lokasi pengamatan semut di sepanjang Jalur Pendakian Cibodas, TNGGP

Penelitian dilakukan di tiga subzona hutan pegunungan sepanjang Jalur Pendakian Cibodas pada enam titik pengambilan sampel (sampling sites), yaitu:

1. Submontana 


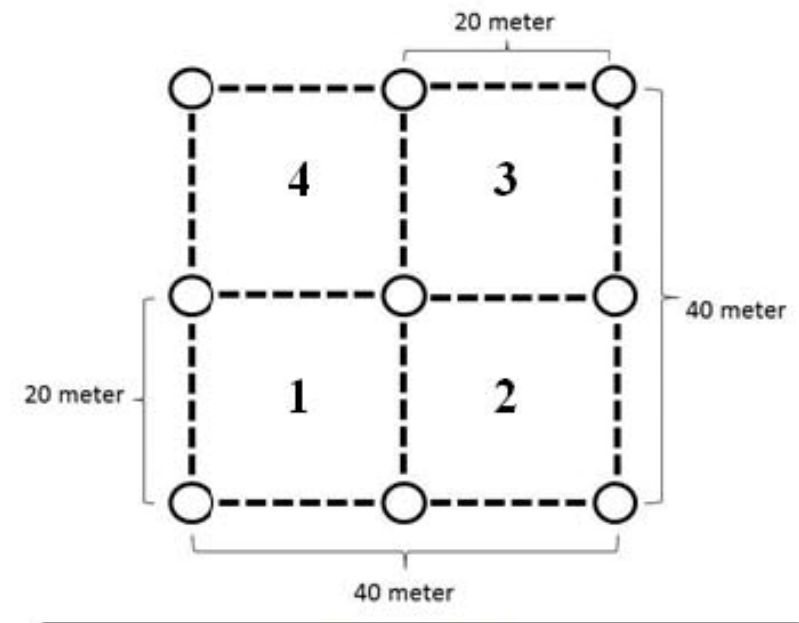

Jalur Pendakian

Keterangan:

$\bigcirc=$ Perangkap sumuran (pit fall trap)

\section{Gambar 2. Model plot penelitian yang digunakan.}

- Telaga Biru, merupakan danau kecil seluas lima hektar di ketinggian 1.575 meter dpl dan terletak 1,5 km dari pintu masuk Cibodas. Plot diletakkan di sekitar telaga.

- Air Terjun Cibeureum, merupakan air terjun yang mempunyai tinggi sekitar 50 meter dan terletak sekitar 2,8 km dari pintu masuk Cibodas. Plot diletakkan di sekitar air terjun.

2. Montana

- $\quad$ Air Panas, terletak sekitar 5,3 km dari pintu masuk Cibodas. Plot diletakkan di sekitar lokasi Air Panas.

- Kandang Badak, merupakan tempat berkemah serta pengamatan tumbuhan dan satwa. Berada pada ketinggian 2.220 meter dpl dengan jarak 7,8 km dari pintu masuk Cibodas. Plot diletakkan di sekitar lokasi perkemahan.

Tabel 1. Keanekaragaman dan Kelimpahan Semut pada Berbagai Subzona Hutan Pegunungan di Sepanjang Jalur Pendakian Cibodas, TNGGP

\begin{tabular}{lllll}
\hline No. & Subfamili & Spesies & Jumlah & Tipe* \\
\hline 1 & Dolichoderinae & Dolichoderus $\mathrm{sp01}$ & 11 & Umum \\
2 & & Dolichoderus $\mathrm{sp02}$ & 84 & Umum \\
3 & Formicinae & Camponotus $\mathrm{sp01}$ & 26 & Umum \\
4 & & Formica $\mathrm{sp01}$ & 72 & Umum \\
5 & & Oecophylla $\mathrm{sp} 01$ & 4 & Predator \\
6 & & Polyrachis $\mathrm{sp01}$ & 12 & Umum \\
7 & Myrmicinae & Myrmica $\mathrm{sp01}$ & 147 & Umum \\
8 & & Myrmica $\mathrm{sp02}$ & 31 & Umum \\
9 & & Pheidole $\mathrm{sp01}$ & 349 & Umum \\
10 & & Solenopsis $\mathrm{sp01}$ & 14 & Umum \\
11 & Ponerinae & Amblyopone $\mathrm{sp01}$ & 32 & Predator \\
12 & & Odontomachus $\mathrm{sp01}$ & 3 & Predator \\
Jumlah & & 785 & \\
\hline
\end{tabular}




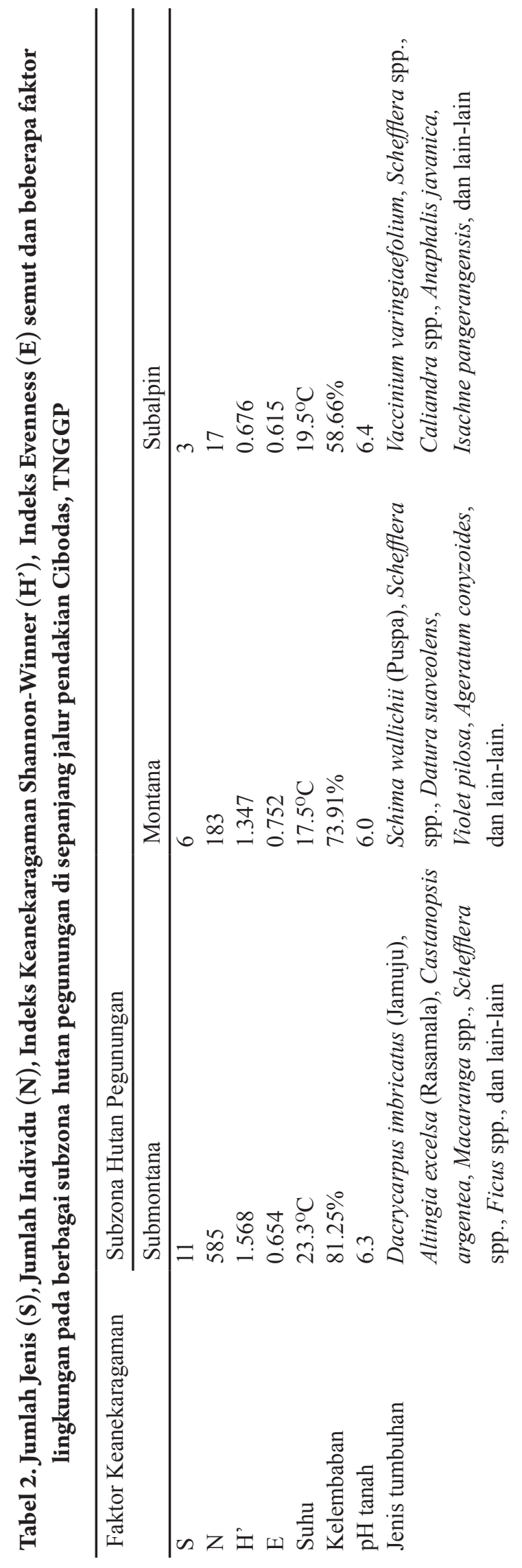


3. Subalpin

- Puncak Gunung Gede Pangrango, merupakan kawasan hutan yang masuk zona subalpin. Terletak di ketinggian hampir 3000 meter dpl.

- Alun-Alun Surya Kencana, merupakan dataran seluas 50 hektar yang ditutupi hamparan bunga Edelweiss dan padang rumput. Terletak pada ketinggian 2.750 meter dpl dengan jarak 11,8 km dari pintu masuk Cibodas.

Setelah menentukan lokasi penelitian hal yang selanjutnya dilakukan adalah membuat Plot Penelitian dan Koleksi Spesimen. Semut dikumpulkan dengan menggunakan perangkap sumuran (pit fall trap) berdiameter $8,5 \mathrm{~cm}$ dan tinggi $9 \mathrm{~cm}$ dalam plot besar berukuran $40 \times 40$ meter yang terdiri atas 4 subplot berukuran $20 \times 20$ meter. Perangkap diletakkan di tiap titik di dalam plot sehingga berjumlah 9 perangkap. Hal ini ditentukan dengan mempertimbangan daya jelajah dari semut yang cukup luas. Plot diletakkan di tiap sampling site sebanyak dua buah secara purposive sampling dengan mempertimbangkan kondisi lapangan yang memungkinkan ditemukan semut dan dipasang perangkap. Perangkap dibiarkan terpasang selama 24 jam dan dilakukan pengulangan sebanyak 3 kali pada masing-masing sampling site pada titik yang sama.

Pada setiap plot penelitian diukur parameter habitat dan lingkungannya. Parameter habitat dan lingkungan yang diambil adalah suhu lingkungan, kelembaban, $\mathrm{pH}$ tanah, dan ketinggian pada masing-masing tempat pengambilan data. Selain itu, dilakukan juga pendataan jenis-jenis tumbuhan yang terdapat di dalam subplot (kuadran) nomor 1 secara umum.

Selanjutnya, untuk pengopsetan dan pengidentifikasian semut dilakukan di Laboratorium Ekologi Universitas Negeri Jakarta. Spesimen diidentifikasi menggunakan kaca pembesar dan mikroskop stereo berdasarkan Borror et al. (1996) dan Hashimoto (2003). Spesimen yang tidak teridentifikasi kemudian ditentukan ke dalam takson spesies berdasarkan perbedaan ciri morfologi (morfospesies). Dari data semut yang dikumpulkan seluruhnya, kemudian dilakukan penghitungan indeks keanekaragaman Shannon-Wiener (H'), indeks Evennes (e), indeks kesamaan Jaccard (Cj) dan Sorenson (Cs) dengan mengacu pada Odum (1971) untuk selanjutnya dianalisis secara deskriptif.

\section{HASIL DAN PEMBAHASAN}

\section{KEANEKARAGAMAN SEMUT PADA BERBAGAI SUBZONA HUTAN PEGUNUNGAN DI SEPANJANG JALUR PENDAKIAN CIBODAS, TNGGP}

Selama penelitian, peneliti telah mengumpulkan dan mengidentifikasi beberapa jenis semut yang ditemukan di sepanjang Jalur Pendakian Cibodas. Beberapa jenis di antaranya merupakan jenis yang umum ditemukan (Tabel 1). Dalam penelitian ini ditemukan sebanyak 785 individu semut yang terdiri atas 4 subfamili (Dolichoderinae, Formicinae, Myrmicinae, dan Ponerinae), dan 12 jenis (Amblyopone sp01, Camponotus sp01, Dolichoderus sp01, Dolichoderus sp02, Formica sp01, Myrmica sp01, Myrmica sp02, Odontomachus sp01, Oecophylla sp01, Pheidole sp01, Polyrachis sp01, dan Solenopsis sp01 (Tabel. 1).

Keanekaragaman semut semakin menurun pada subzona hutan pegunungan yang berada pada ketinggian yang lebih tinggi. Hal ini juga didukung oleh analisis keanekaragaman dengan indeks keanekaragaman ShannonWinner dan Evenness-nya yang menunjukkan adanya kecenderungan yang sama yaitu semakin rendah ketinggian 
maka semakin tinggi indeks keanekaragaman dan Evenness-nya (Tabel 2). Nilai evenness yang tinggi menunjukkan tingginya kesamarataan kelimpahan antarspesies pada subzona hutan pegunungan.

Tabel 3. Indeks persamaan Jaccard $(\mathrm{C} j)$ semut pada berbagai subzona hutan pegunungan di sepanjang jalur pendakian Cibodas, TNGGP.

\begin{tabular}{llll}
\hline Subzona Hutan Pegunungan & Submontana & Montana & Subalpin \\
\hline Submontana & - & & \\
Montana & 0.417 & - & \\
Subalpin & 0.167 & 0.500 & - \\
\hline
\end{tabular}

Tabel 4. Indeks persamaan Sorensen (Cs) semut pada berbagai subzona hutan pegunungan di sepanjang jalur pendakian Cibodas, TNGGP

\begin{tabular}{llll}
\hline Subzona Hutan Pegunungan & Submontana & Montana & Subalpin \\
\hline Submontana & - & & \\
Montana & 0.588 & - & \\
Subalpin & 0.334 & 0.667 & - \\
\hline
\end{tabular}

Pada subzona hutan pegunungan submontana terdapat 11 jenis dari 585 individu semut yang ditemukan dengan indeks keanekaragaman dan indeks Evenness-nya masing-masing sebesar 1,568 dan 0,654. Untuk subzona hutan pegunungan montana terdapat 6 jenis dari 183 individu semut yang ditemukan dengan indeks keanekaragaman dan indeks Evenness-nya masing-masing sebesar 1,347 dan 0,752. Sementara itu, pada subzona hutan pegunungan subalpin terdapat 3 jenis dari 17 individu semut yang ditemukan dengan indeks keanekaragaman dan indeks Evennessnya masing-masing sebesar 0,676 dan 0,615. Keanekaragaman tertinggi terdapat pada subzona hutan pegunungan submontana lalu diikuti oleh montana dan terkecil subalpin.

Dari hasil pengamatan beberapa parameter fisik lingkungan didapatkan bahwa kelembaban tertinggi terdapat di subzona hutan pegunungan submontana yaitu $81,25 \%$ lalu di montana dan subalpin masing-masing-masing $76,91 \%$ dan 58,66\%. Suhu tertinggi terletak di subzona hutan pegunungan montana dengan $23,3 \mathrm{oC}$ dan terendah pada montana yaitu 17,5oC. Keasaman tanah $(\mathrm{pH})$ antara submontana, montana, dan subalpin masing-masing 6,3; 6,$0 ;$ dan 6,4 .

Keanekaragaman semut di subzona hutan pegunungan montana lebih tinggi dibandingkan subzona hutan pegununganlainnya. Keanekaragaman semutyanglebih tinggiini disebabkan oleh tingginyakeanekaragaman makhluk hidup pada ketinggian tersebut, baik hewan maupun tumbuhan. Berdasarkan Kahono (2007), keanekaragaman jenis hewan pada ketinggian hutan bagian kaki gunung lebih tinggi daripada di bagian yang lebih tinggi lainnya. Namun, belum ada publikasi yang mengaitkan tentang keanekaragaman jenis semut dengan keanekaragaman makhluk hidup yang ada di Taman Nasional Gunung Gede-Pangrango.

Sebagian besar jenis semut yang ditemukan pada subzona hutan pegunungan submontana merupakan tipe umum berdasarkan jenis pakan mengacu pada Hashimoto (2003). Jenis ini merupakan tipe yang paling kosmopolit karena memiliki variasi makan yang lebih banyak sehingga tidak terlalu bergantung pada pakan tertentu. Berdasarkan indeks keanekaragaman dan indeks Evenness, didapatkan keanekaragaman tertinggi pada subzona hutan pegunungan submontana dengan indeks keanekaragaman dan indeks Evenness-nya masing-masing sebesar 1,568 dan 0,654.

Perbedaan ketinggian pada masing-masing subzona hutan pegunungan menyebabkan terjadinya perbedaan 
faktor biotik dan abiotik di dalamnya. Ketika satu faktor lingkungan berbeda, hal ini tentunya akan menyebabkan terjadinya perbedaan pada faktor lingkungan yang lain. Faktor ketinggian secara tidak langsung mempengaruhi suhu lingkungan. Suhu merupakan faktor pembatas yang dapat mempengaruhi keanekaragaman makhluk hidup, di antaranya tumbuhan. Beberapa tumbuhan tertentu spesifik ditemukan di salah satu subzona hutan namun tidak ditemukan lagi di subzona hutan lainnya. Tentunya, keanekaragaman tumbuhan ini sangat erat kaitannya dengan sumber pakan dan sarang sementara keanekaragaman hewan sangat berkaitan terhadap beberapa jenis semut predator maupun dekomposer (Borror et al., 1996).
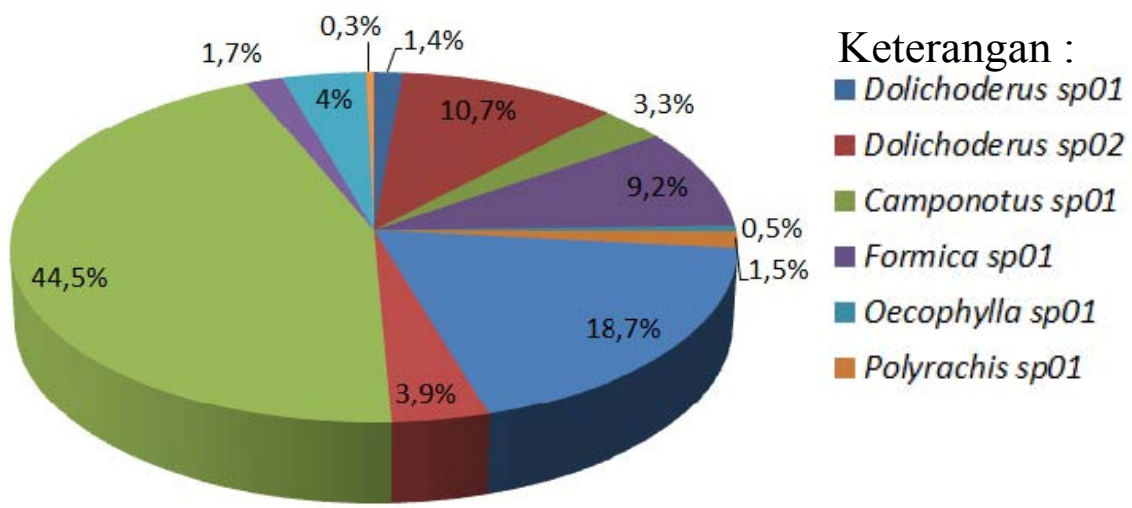

Myrmica sp01

Myrmica sp02

Pheidole sp01

Solenopsis sp01

Amblyopone sp01

Odontomachus sp01

\section{Gambar 3. Diagram kelimpahan spesies semut pada berbagai subzona hutan pegunungan di sepanjang Jalur Pendakian Cibodas.}

Indeks persamaan Jaccard yang tertinggi adalah 0,500 (Tabel 3), berarti 50\% berdasarkan jumlah jenis yang ditemukan pada kedua subzona hutan pegunungan adalah jenis yang sama. Jenis yang tidak jauh berbeda lebih banyak ditemukan pada subzona hutan pegunungan montana dengan subalpin. Indeks persamaan Sorensen yang tertinggi adalah 0,667 (Tabel 4), berarti 66\% berdasarkan jumlah jenis yang ditemukan pada kedua subzona hutan pegunungan adalah jenis yang sama. Meskipun pada kedua subzona hutan pegunungan ini, yaitu montana dan subalpin, memiliki keanekaragaman yang lebih rendah namun memiliki kesamaan jenis yang lebih tinggi dibandingkan dengan yang lainnya. Kesamaan jenis di antara dua subzona hutan pegunungan tersebut tidak jauh berbeda.

Dari hasil pengamatan, beberapa parameter fisik lingkungan didapatkan bahwa kelembaban tertinggi terdapat di subzona hutan pegunungan submontana yaitu 81,25\% lalu di montana dan subalpin masing-masing-masing 76,91\% dan 58,66\%. Hal ini menunjukkan terjadi penurunan tingkat kelembaban di berbagai lokasi pengamatan. Hal ini disebabkan dengan intensitas cahaya matahari yang semakin kuat. Namun, belum ada publikasi yang menunjukkan hubungan antara kelembaban dengan keanekaragaman semut sehingga belum dapat diambil kesimpulan secara pasti bahwa kelembaban adalah faktor pembatas yang mempengaruhi keanekaragaman semut.

Suhu tertinggi terletak di subzona hutan pegunungan montana dengan $23,3^{\circ} \mathrm{C}$ dan terendah pada montana yaitu $17,5^{\circ} \mathrm{C}$. Sekalipun subzona hutan pegunungan subalpin berada lebih dekat dengan matahari, angin yang kencang menyebabkan suhu di subzona hutan pegunungan subalpin lebih sejuk dibandingkan submontana.

Keasaman tanah $(\mathrm{pH})$ antara submontana, montana, dan subalpin secara umum tidak jauh berbeda yaitu masing-masing 6,3; 6,0; dan 6,4. Yang sangat membedakan adalah kondisi tanahnya. Pada Alun-Alun Suryakencana banyak diisi oleh bebatuan vulkanik yang keras sehingga tidak gembur sama sekali. Hal ini sulit bagi semut yang akan membangun sarang atau aktivitas menanam telur. Sangat berbeda dengan lokasi lainnya yang memiliki tanah 
yang lebih gembur dan subur karena banyak ditumbuhi oleh berbagai jenis tumbuhan, terutama di subzona hutan pegunungan submontana. Hal inilah yang menyebabkan keanekaragaman hewan dan tumbuhan di daerah tersebut sangat tinggi. Pada subzona hutan pegunungan subalpin masih ditemukan semut karena lokasi pengambilan sampel yang masih berdekatan dengan subzona hutan montana sehingga kondisi tanah tidak terlalu berbatu dan masih ditemukan beberapa jenis tumbuhan.

Sepanjang jalur pendakian banyak ditumbuhi oleh berbagai jenis tumbuhan, di mana untuk subzona hutan pegunungan submontana banyak didominasi oleh Rasamala sementara untuk subzona hutan pegunungan montana banyak didominasi oleh Pohon Puspa. Di Alun-Alun Suryakencana tidak ditemukan lagi pohon kecuali hamparan padang rumput saja. Tentunya ini akan sangat mempengaruhi berbagai jenis makhluk hidup lainnya yang berada di sana, termasuk salah satunya semut sebagai bagian dari ekosistem yang memiliki peran tersendiri dalam relungnya. Berkurangnya kompleksitas ekosistem tentunya akan sangat mempengaruhi keanekaragaman semut.

\section{Tabel 5. Distribusi semut pada berbagai subzona hutan pegunungan di sepanjang jalur pendakian Cibodas, TNGGP}

\begin{tabular}{|c|c|c|c|c|c|c|c|c|}
\hline \multirow[b]{2}{*}{ Subfamili } & \multirow[b]{2}{*}{ Jenis } & \multicolumn{2}{|c|}{ Submontana } & \multicolumn{2}{|c|}{ Montana } & \multicolumn{3}{|c|}{ Subalpin } \\
\hline & & 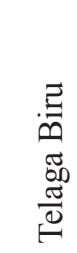 & 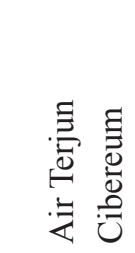 & 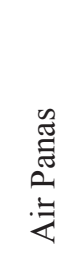 & 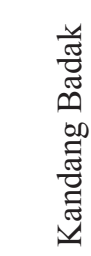 & 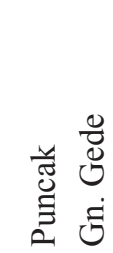 & 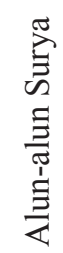 & 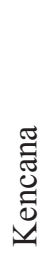 \\
\hline \multirow[t]{2}{*}{ Dolichoderinae } & Dolichoderus sp01 & 7 & 4 & - & - & - & - & \\
\hline & Dolichoderus sp02 & - & - & 72 & 9 & 3 & - & \\
\hline \multirow[t]{4}{*}{ Formicinae } & Camponotus sp01 & 19 & 7 & - & - & - & - & \\
\hline & Formica sp01 & 22 & 16 & 13 & 10 & 1 & - & \\
\hline & Oecophylla sp01 & 4 & - & - & - & - & - & \\
\hline & Polyrachis sp01 & 10 & 2 & - & - & - & - & \\
\hline \multirow[t]{4}{*}{ Myrmicinae } & Myrmica $\mathrm{sp} 01$ & 76 & 63 & 4 & 4 & - & - & \\
\hline & Myrmica $\mathrm{sp} 02$ & 22 & 9 & - & - & - & - & \\
\hline & Pheidole sp01 & 167 & 111 & 35 & 23 & 13 & - & \\
\hline & Solenopsis sp01 & 6 & 5 & 3 & - & - & - & \\
\hline \multirow[t]{2}{*}{ Ponerinae } & Amblyopone sp01 & 15 & 7 & 10 & - & - & - & \\
\hline & Odontomachus sp01 & 3 & - & - & - & - & - & \\
\hline
\end{tabular}

\section{KELIMPAHAN SEMUT PADA BERBAGAI SUBZONA HUTAN PEGUNUNGAN DI SEPANJANG JALUR} PENDAKIAN CIBODAS, TNGGP

Dari hasil penelitian, didapatkan kelimpahan total sebanyak 785 individu dari 12 jenis yang ditemukan di sepanjang jalur pendakian. Kelimpahan semut bervariasi berdasarkan jenis yang ditemukan. Kelimpahan individu semut pada setiap Jenis yang tertinggi adalah Pheidole sp01 (349 individu atau 44,5\% dari seluruh individu yang ditemukan), disusul berturut-turut oleh Myrmica sp01 (147 individu atau 18,7\%), Dolichoderus sp02 (84 individu atau 10,7\%), Formica sp01 (72 individuatau 9,2\%), Amblyopone sp01 (32 individu atau 4,0\%), Myrmica sp02 (31 individu atau 3,9\%), Camponotus sp01 (26 individu atau 3,3\%), Solenopsis sp01 (14 individu atau 1,7\%), Polyrachis sp01 (12 individu atau 1,5\%), Dolichoderus sp01 (11 individu atau 1,4\%), Oecophylla sp01 (4 individu atau 0,5\%), 
dan Odontomachus sp01 (3 individu atau 0,3\%).

Kelimpahan semut secara umum mengalami penurunan seiring dengan meningkatnya ketinggian tempat dari permukaan laut (Tabel 5). Penurunan kelimpahan ini disebabkan oleh berbagai faktor, di antaranya keanekaragaman tumbuhan dan hewan serta faktor fisik lingkungan seperti suhu, kelembaban, dan kondisi tanah.

Pada subzona hutan pegunungan submontana memiliki keanekaragaman jenis tumbuhan dan hewan yang lebih tinggi dibandingkan subzona hutan pegunungan montana dan subalpin (Dephut, 2012). Kondisi ini secara tidak langsung dapat mempengaruhi keanekaragaman semut, terutama kelimpahannya.

DISTRIBUSI SEMUT PADA BERBAGAI SUBZONA HUTAN PEGUNUNGAN DI SEPANJANG JALUR PENDAKIAN CIBODAS, TNGGP

Dari 6 titik pengambilan sampel pada 3 subzona hutan pegunungan, yaitu Telaga Biru dan Air Terjun Cibeureum untuk kawasan submontana; Air Panas dan Kandang Badak untuk kawasan montana; dan Puncak Gunung Gede dan Alun-Alun Suryakencana untuk kawasan subalpin, didapatkan keanekaragaman tertinggi pada subzona hutan pegunungan submontana.

Jenis seperti Formica sp01 dan Pheidole sp01 memiliki distribusi yang lebih luas dibandingkan yang lainnya karena ditemukan pada setiap tempat pada berbagai subzona hutan pegunungan kecuali di Alun-Alun Suryakencana. Jenis lainnya seperti Myrmica sp01 memiliki distribusi yang lebih sempit yaitu hanya ditemukan sampai subzona hutan pegunungan montana, berbeda dengan Dolichoderus sp02 yang masih dapat ditemukan di Puncak Gunung Gede meskipun jenis ini tidak didapat di subzona hutan pegunungan submontana. Namun dari genus yang sama, Dolichoderus sp01, dapat ditemukan di subzona hutan tersebut meskipun tidak didapatkan lagi di subzona hutan yang lebih tinggi (Tabel 5). Beberapa jenis seperti Camponotus sp01, Polyrachis sp01, dan Myrmica sp02 hanya didapatkan di subzona hutan pegunungan submontana, bahkan jenis lainnya seperti Oecophylla sp01 dan Odontomachus sp01 hanya ditemukan pada lokasi Telaga Biru saja.

Dari 6 titik pengambilan sampel pada 3 subzona hutan pegunungan, yaitu Telaga Biru dan Air Terjun Cibeureum untuk kawasan submontana; Air Panas dan Kandang Badak untuk kawasan montana; dan Puncak Gunung Gede dan Alun-Alun Suryakencana untuk kawasan subalpin, didapatkan keanekaragaman tertinggi pada subzona hutan pegunungan submontana. Hal ini menunjukkan bahwa kondisi habitat di kawasan submontana lebih baik bagi semut dibandingkan subzona hutan di atasnya.

Jenis seperti Formica sp01 dan Pheidole sp01 memiliki distribusi yang lebih luas dibandingkan yang lainnya karena ditemukan pada setiap tempat pada berbagai subzona hutan pegunungan kecuali di Alun Suryakencana. Jenis ini merupakan jenis yang kosmopolit dan sering ditemukan berkoloni dengan jumlah yang banyak. Jenis lainnya seperti Myrmica sp01 memiliki distribusi yang lebih sempit yaitu hanya ditemukan sampai subzona hutan pegunungan montana, berbeda dengan Dolichoderus sp02 yang masih dapat ditemukan di Puncak Gunung Gede meskipun jenis ini tidak didapat di subzona hutan pegunungan submontana. Namun dari genus yang sama, Dolichoderus sp01, dapat ditemukan di subzona hutan tersebut meskipun tidak didapatkan lagi di subzona hutan yang lebih tinggi.

Pada Alun-Alun Suryakencana sama sekali tidak ditemukan semut. Hal ini disebabkan oleh beberapa faktor. Dalam ekologi, ada faktor pembatas yang membatasi keanekaragaman dan kelimpahan suatu jenis makhluk hidup (Odum, 1971). Faktor pembatas itu dapat berupa suhu, kelembaban, atau pun kondisi tanah yang merupakan bagian dari tempat aktivitas semut, baik dalam mencari makan atau membangun sarang. Berdasarkan pengamatan, peneliti mencatat bahwa suhu di Alun Suryakencana ketika dini hari dapat mencapai $8^{\circ} \mathrm{C}$. Tentunya kondisi ini tidak ideal 
bagi semut karena suhu ideal sarang semut berkisar antara $20-30^{\circ} \mathrm{C}$ (Farb, 1983). Dengan suhu yang sangat rendah ini menyebabkan larva dan pupa tidak dapat berkembang dengan baik (Borror et al., 1996).

\section{KESIMPULAN}

Berdasarkan hasil penelitian dan pembahasan dapat disimpulkan bahwa keanekaragaman jenis semut (Hymenoptera: Formicidae) pada berbagai subzona hutan pegunungan di sepanjang Jalur Pendakian Cibodas didapatkan 4 subfamili dan 12 jenis semut dengan indeks keanekaragaman semut pada subzona hutan pegunungan submontana, montana, dan subalpin masing-masing sebesar 1,568; 1,347, dan 0,676.

\section{DAFTAR PUSTAKA}

Borror, D.J., Triplehorn, C. A., Jhonson, N. F. (1996). Pengenalan Pelajaran Serangga. Diterjemahkan oleh Partosoedjono. Edisi keenam. Yogyakarta: Penerbit Gadjah Mada University Press

Departemen Kehutanan.(2012). TamanNasional GunungGede-Pangrango.http://www.dephut.go.id/INFORMASI/ TN\%20INDO-ENGLISH/tn_gedepangrango.htm, 4 April 2012, pk. 23.21 WIB.

Farb, P. (1983). Serangga. Terj. dari The Insects oleh S. Timan. Pustaka Time-Life: 192 hlm.

Hoeve, W. van. (1996). Ensiklopedi Indonesia Seri Fauna: Serangga. Terj. dari Encyclopedie van het Dierenrijk. PT Ichtiar Baru Van Hoeve: $256 \mathrm{hlm}$.

Kahono, S., \& Setiadi, L. K. (2007). Keanekaragaman dan Distribusi Vertikal Kumbang Tinja Scarabaeids (Coleoptera: Scarabaeidae) di Hutan Tropis Basah Pegunungan Taman Nasional Gede Pangrango, Jawa Barat, Indonesia. Biodiversitas. 7 (4). ISSN 1412-033X.

Odum, E. P. (1971). Dasar-Dasar Ekologi. Terj. dari Fundamentals of Ecology, oleh Tjahjono Samingan dan Srigandono. Gadjah Mada University Press, Yogyakarta: xv +697 hlm.

Schultz, T. R. (2000). In Search of Ant Ancestors. PNAS. 97 (26): 14028-14029.

Shahabuddin, Hidayat, P., Nordjito, W. A., \& Manuwoto, S. (2005). Review: Penelitian Biodiversitas Serangga di Indonesia: Kumbang Tinja (Coleoptera: Scarabaeidae) dan Peran Ekosistemnya. Biodiversitas. 6 (2). ISSN: 1412-033x 